\title{
Effectiveness of Distant Healing for Patients with Chronic Fatigue Syndrome: A Randomised Controlled Partially Blinded Trial (EUHEALS)
}

\author{
Harald Walach ${ }^{\text {a,d }}$ Holger Bösch ${ }^{d}$ George Lewith $^{b}$ Johannes Naumann ${ }^{d}$ \\ Barbara Schwarzer $^{d}$ Sonja Falk ${ }^{d}$ Niko Kohls $^{a}$ Erlendur Haraldsson ${ }^{f}$ \\ Harald Wiesendanger ${ }^{\mathrm{e}}$ Alain Nordmann ${ }^{\mathrm{h}}$ Helgi Tomasson $^{\mathrm{g}}$ Phil Prescott $^{\mathrm{c}}$ \\ Heiner C. Bucher ${ }^{\text {h }}$

\begin{abstract}
a Samueli Institute, European Office, School of Social Sciences, University of Northampton, Northampton, Departments of ${ }^{b}$ General Practice, and ' Statistics, University of Southampton, Southampton, UK;

${ }^{\mathrm{d} C A M}$ Outpatients Department, University Hospital Freiburg, Institute of Environmental Medicine and

Hospital Epidemiology, Freiburg, ${ }^{e}$ Private Practice, Schönbrunn, Germany; ${ }^{\mathrm{f}}$ Department of Social Sciences, and ${ }^{9}$ Faculty of Economics and Business Administration, University of Iceland, Reykjavik, Iceland;

${ }^{\mathrm{h}}$ Basel Institute for Clinical Epidemiology, University Hospital Basel, Basel, Switzerland
\end{abstract}

\section{Key Words}

Chronic fatigue syndrome $\cdot$ Distant healing .

Complementary and alternative medicine

\begin{abstract}
Background: Distant healing, a form of spiritual healing, is widely used for many conditions but little is known about its effectiveness. Methods: In order to evaluate distant healing in patients with a stable chronic condition, we randomised 409 patients with chronic fatigue syndrome (CFS) from 14 private practices for environmental medicine in Germany and Austria in a two by two factorial design to immediate versus deferred (waiting for 6 months) distant healing. Half the patients were blinded and half knew their treatment allocation. Patients were treated for 6 months and allocated to groups of 3 healers from a pool of 462 healers in 21 European countries with different healing traditions. Change in Mental Health Component Summary (MHCS) score (SF-36)
\end{abstract}

was the primary outcome and Physical Health Component Summary score (PHCS) the secondary outcome. Results: This trial population had very low quality of life and symptom scores at entry. There were no differences over 6 months in post-treatment MHCS scores between the treated and untreated groups. There was a non-significant outcome $(p=$ $0.11)$ for healing with PHCS $(1.11 ; 95 \% \mathrm{Cl}-0.255$ to 2.473 at 6 months) and a significant effect ( $p=0.027)$ for blinding; patients who were unblinded became worse during the trial $(-1.544 ; 95 \% \mathrm{Cl}-2.913$ to -0.176$)$. We found no relevant interaction for blinding among treated patients in MHCS and PHCS. Expectation of treatment and duration of CFS added significantly to the model. Conclusions: In patients with CFS, distant healing appears to have no statistically significant effect on mental and physical health but the expectation of improvement did improve outcome.

Copyright $\odot 2008$ S. Karger AG, Basel

School of Social Sciences and Samueli Institute for Information Biology

University of Northampton, Boughton Green Road

Northampton NN2 7AL (UK)

Tel. +44 1604892 952, Fax +44 1604722 067, E-Mail harald.walach@northampton.ac.uk 


\section{Introduction}

The use of complementary and alternative medicine (CAM) is increasing and is strongly associated with belief in the effectiveness of mental and spiritual factors $[1,2]$. In a US survey, $7 \%$ of individuals had tried spiritual healing [1]. Spiritual healing is a 'broad' therapy and may be defined as an intentional therapeutic influence of one or more persons upon another individual without utilizing known physical means of interventions [3]. It encompasses prayer and healing, either by touch or distantly [4-11] and plays an important role in the traditional healing systems of Northern Europe, Africa and Asia. Despite its widespread use evidence for efficacy is scarce. In systematic reviews of randomised controlled trials comparing distant healing versus placebo or control treatment the results from individual trials were extremely heterogeneous. Methodological limitations of included trials precluded any firm conclusion about the efficacy of distant healing and there is clearly a need for more rigorous trials $[12,13]$. Since the publication of these systematic reviews, three randomized controlled double-blind trials of remote group prayer in intensive coronary care unit patients have been published. One trial found an improvement in intensive care scores [14]. The other two, looking at welldefined clinical endpoints, found no clinical effect [15, 16]. A recent study of distant healing in AIDS [17] was unable to reproduce previous positive pilot results [18].

We intentionally chose patients with chronic fatigue syndrome (CFS) because available treatment options for patients with CFS, such as cognitive behaviour therapy [19] or graded exercise therapy [20], are not generally effective $[21,22]$, or widely available and only used by some CFS patients because of their own individual attributional theories about this illness [23]. As patients with CFS are regularly seeking alternative treatments and may frequent healers, this would appear to be a reasonable intervention to evaluate.

Our goal was to evaluate the effectiveness of distant healing for patients with CFS. We also wished to assess the effects of expectation without using deception and hence provided the healing intervention both with and without the patients' knowledge. As a control condition, patients had to wait for the healing intervention, both with and without knowing their group assignment. We were therefore able to assess the effect of expectation in this $2 \times 2$ factorial design as it involved two factors: 'treatment' (immediate or deferred treatment) and the participants' 'knowledge', i.e. whether they were informed about their treatment or not.

Effectiveness of Distant Healing for Patients with Chronic Fatigue Syndrome

\section{Method}

Details of the study design have been published elsewhere [24]. The trial was investigator-initiated, conducted according to Good Clinical Practice rules and approved by the ethics committee of the University Hospital Freiburg (Approval No. 60/2001). We report the trial results following the Consolidated Standards of Reporting Trials guidelines [25].

\section{Patients}

Patients included into the trial had to be 18 years of age or older and fulfil the Fukuda criteria for chronic fatigue or the Oxford criteria for severe idiopathic CFS [26]. Patients with other chronic conditions or co-morbidity that typically rules out a diagnosis of CFS (e.g. cancer, hepatitis, or depression) were excluded as was pregnancy and patients with a serious or acute illness or hospital admission in the 3 months prior to entry. Clinical assessments were conducted by the recruiting physicians, based on their clinical evaluation and appropriate laboratory data. Patients were recruited between October 2001 and May 2003 from 14 private practices in Germany and Austria by doctors that specialised in the treatment of CFS and who normally use an environmental medical approach for this diagnosis which includes the prescription of nutritional supplements and other complementary therapies such as homeopathy and herbal medicine. We recruited the majority of patients through an information campaign and coverage in national newspapers, radio and TV. We directed patients to the trial coordination centre (H.B.) in Freiburg. The trial coordination centre ascertained potential eligibility by phone and sent patients for final check of eligibility and inclusion to one of the 14 recruitment centres. The informed consent, a case report form and the baseline questionnaires were sent to the trial coordination centre. Three portrait photographs were taken, sent to the healer coordinator (H.Wi.) and following treatment allocation, forwarded to the healers. The trial coordination centre forwarded the patient identification number for randomisation to the trial auditor (G.L.) in the UK.

\section{Interventions}

The trial followed a two by two factorial design with the factors 'blinded versus un-blinded treatment' and 'immediate versus deferred treatment'. Of the two groups randomised to immediate treatment, one group was informed that they were being healed, while the other was not. Two further groups were allocated to the deferred treatment with distant healing, one of these groups was informed that they would have to wait 6 months for treatment, the other was not.

Following randomisation by the trial auditor the identification number, the first name, and the portrait pictures of patients assigned to distant healing were forwarded to the healer coordinator. Based on a random assignment code, the healer coordinator assigned 3 healers to each incoming patient and forwarded the surname and the pictures to the healers. Healers were replaced if they lived within $100 \mathrm{~km}$ of the patient's residence to minimise the chance of incidental contact. Each patient was treated by 3 healers to guarantee minimal coverage in case of dropout or ineffective distant healing. Patients and treating physicians were free to use any additional concomitant treatment during the entire trial period. 
Healers were self-referred or recommended through national healing organisations to the healer coordinator. Healers were from many different healing traditions and practiced distant healing individually or in groups by either prayer or by imagining the transmission of 'healing energy', 'light' or 'healing power' to patients. They were free to adopt any scheme of healing intensity and frequency in accordance with their normal practice.

Healers had to complete a weekly healing report for the healing coordinator to document the time, duration and type of distant healing for each patient. If the report was not sent back in time, the healer was contacted by the healer coordinator and noncompliant healers were replaced. The monitoring centre (A.N.) contacted a random sample of $20 \%$ of healers by phone and checked whether they had complied with the study protocol.

Our pragmatic selection criteria for healers were: healers had to have experience with distant healing and declare that they believed in its clinical effects. Healers had to confirm to the investigators that during their other healing practice they did not interfere with conventional medical treatment, did not diagnose patients or accept advance payments from patients or encourage or indulge in sexual relationships with patients. All healers were informed about the nature of the trial and patient inclusion criteria. They were happy to have a patient's name, picture and diagnosis, a procedure in line with their normal healing practice. We collected basic sociodemographic data from each healer as well as details of their type of healing practice.

\section{Outcome Measures}

The predefined primary endpoint of the trial was self-reported mental health as measured with the Mental Health Component Summary (MHCS) score of the validated German version of the general health questionnaire (SF-36) [27]. The secondary endpoint was self-reported physical health based on the Physical Health Component Summary (PHCS) score (SF-36). We used this generic quality of life instrument based on our pilot work with CFS, although we now know that this questionnaire may have limited sensitivity to detect clinical change in this condition [28]. However, it is widely used for assessing generic outcomes in both CFS as well as many other chronic conditions [29].

At baseline, we recorded the patients' demographic characteristics. We measured depression with the German version of the Centre of the Epidemiologic Study of Depression Scale (Allgemeine Depressions-Skala) [30], fatigue with the Fatigue Severity Scale [31], health beliefs with the Holistic Complementary and Alternative Medicine Questionnaire, a questionnaire specifically designed to assess beliefs in CAM [32], treatment credibility and expectations with the Treatment Credibility and Expectancy Scale [33]. This is a validated scale used to assess treatment expectations and credibility in the context of many types of psychological intervention. We also measured religious beliefs and practices with single items. The SF-36 was completed at entry into the study and 6 months after recruitment. All measures were completed before randomisation and at the second time point, before patients were unblinded, if applicable.

\section{Randomisation}

Allocation of patients to the 4 groups was concealed by a computer algorithm generated at the remote randomisation site in Iceland (H.T.). The randomisation code was forwarded to the trial auditor in the UK. With the use of a second single randomisa- tion procedure, this code was converted by the assistant of the trial auditor (G.L.) to guarantee the complete blinding of all investigators. This assistant had no contact with patients or investigators and was the only person with access to the second code. The assistant sent three different standard letters to the patients, in accordance with their allocation, containing the level of information predefined in the trial protocol and a pre-stamped postcard with the request to the patient to send it to the monitoring centre. The trial auditor notified the monitoring centre about each newly recruited patient. The monitoring centre then verified that all randomised patients had been notified about their inclusion. If a patient did not report back 2 weeks following the randomisation, the monitoring centre phoned the patient to verify that the patient had been included and received the information. Two written reminders and a final telephone reminder ensured a high return rate of the post-treatment SF-36. Patients allocated to blinded distant healing or blinded waiting, the physicians responsible for their care, the healers, and all the investigators, including the biostatistician involved in the final analysis, were blind to treatment allocation prior to completion of the analysis.

\section{Data Handling and Monitoring}

The trial coordination centre was responsible for data verification and entry. Staff involved in data handling and entry was blind to the treatment allocation of patients. All data were entered via content capturing software (Teleform 7.0, Electric Paper, Cardiff, UK). All scanned data were double checked visually. At trial completion, the integrity of the final database was checked by the trial monitor.

\section{Sample Size}

In a previous pilot study of distant healing in patients with different chronic conditions [34], we found a 10-point difference in the SF-36. This difference corresponds to a standardized mean difference of $d=0.66$ in the sum scale for distant healing against a waiting list control. We assumed the effect size in patients with CFS would be smaller because of the chronicity and severity of the condition, the more rigorous trial design and because we allowed for absolutely no contact between healers and patients. Therefore, we estimated an effect size of $d=0.40$ in the MHCS (SF-36) as our primary outcome and an effect size in MHCS of $d=0.20$ as significant in predicting an interaction for blinded versus unblinded treatment. We consider an effect size of $\mathrm{d}=0.20$ as clinically relevant. Assuming a power of $80 \%$ and a dropout rate of $20 \%, 100$ patients in each arm (400 in total) were needed to detect the presence of an effect or interaction of $d=0.20$ [35].

\section{Statistics}

Data were analysed using intention to treat. MHCS and PHCS scores were calculated according to the SF-36 manual. Missing data were interpolated according to the SF-36 manual with pretreatment measurements being interpolated by grand means and by last-value-carried-forward algorithms for missing post-treatment measurements. Differences in post-treatment score values between groups were calculated using analyses of covariance fitted by a general linear model with pre-treatment values being included as baseline co-variates, as defined in the protocol. Additional co-variates to enter the model were specified at an investigators meeting after reviewing the analysis of the main group effect and prior to breaking the code of the blinded analysis. Apart 


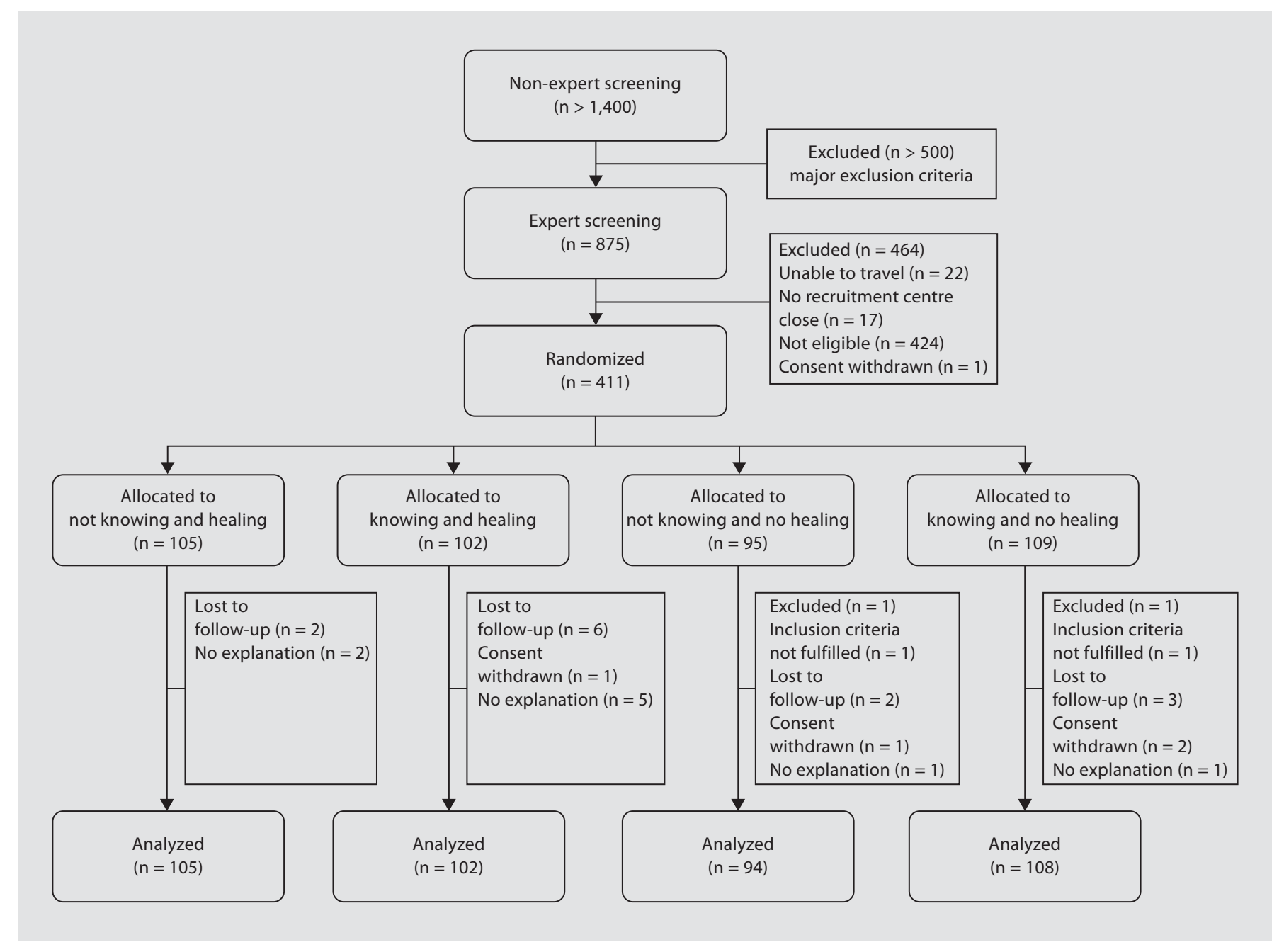

Fig. 1. Study flow with outcome assessment in the EUHEALS trial of distant healing in patients with CFS.

from the main effects e.g. treatment and patient blinding for the intervention, age, gender, treatment credibility and expectations of patients, duration and severity of CFS were entered into the model. Predictors not contributing to the model with a $\mathrm{p}$ value $<0.05$ were then deleted in the final model. All statistical analyses were done using MINITAB version 14.

Post hoc Analysis and Follow-Up

Before telling blinded patients which group they had been allocated to, we asked them whether they thought they had received healing during the study. In addition, we sent out a third SF-36 questionnaire 6 months after the last patients had completed the study to evaluate long-term outcome. This meant that for the patients recruited into the study right at the beginning the follow-up time was 18 months. On average, however, follow-up time was similar for patients of all groups.

Effectiveness of Distant Healing for Patients with Chronic Fatigue Syndrome

\section{Results}

\section{Recruitment of Healers, the Intervention and Participant Flow}

Distant healing was provided by 462 healers from 21 European countries. Healers had a mean healing experience of 9.7 years $(\mathrm{SD}=7.9)$, a mean age of $51(\mathrm{SD}=10.9)$ and were predominantly female (63\%). Commonly used techniques for healers in their normal practice were laying-on of hand (73\%), healing prayer (52\%), healing meditation (40\%), Reiki (33\%) and chakra therapy (32\%). The majority of healers practiced part-time (48\%), 31\% practiced full time, while $21 \%$ practiced occasionally. The mean duration of distant healing sessions reported in the healers' diaries was $20.14 \mathrm{~min}(\mathrm{SD}=13.1)$. Thirty-four

Psychother Psychosom 2008;77:158-166 
Table 1. Baseline characteristics of trial participants

\begin{tabular}{|c|c|c|c|c|}
\hline & $\begin{array}{l}\text { Blinded and } \\
\text { distant healing } \\
(\mathrm{n}=105)\end{array}$ & $\begin{array}{l}\text { Not blinded and } \\
\text { distant healing } \\
(\mathrm{n}=102)\end{array}$ & $\begin{array}{l}\text { Blinded and no } \\
\text { distant healing } \\
(n=94)\end{array}$ & $\begin{array}{l}\text { Not blinded } \\
\text { and no healing } \\
(\mathrm{n}=108)\end{array}$ \\
\hline Age, years & $47.5 \pm 10.7$ & $48.1 \pm 10.0$ & $46.2 \pm 10.9$ & $50.4 \pm 12.8$ \\
\hline Female, $\%$ & 74.3 & 76.5 & 76.6 & 75.0 \\
\hline Education, \% with $\geq 13$ years & 48 & 36 & 55 & 42 \\
\hline Unemployment, months & $36.3 \pm 38.2$ & $34.8 \pm 49.6$ & $27.7 \pm 22.3$ & $28.7 \pm 27.4$ \\
\hline Duration of CFS, years & $11.3 \pm 9.4$ & $9.6 \pm 6.7$ & $9.6 \pm 8.6$ & $11.9 \pm 9.9$ \\
\hline Severe idiopathic CFS, \% & 7.6 & 2.9 & 4.3 & 3.7 \\
\hline Fatigue severity score ${ }^{a}$ & $6.2 \pm 0.9$ & $6.1 \pm 0.9$ & $6.1 \pm 1.1$ & $6.0 \pm 1.1$ \\
\hline Credibility of distant healing, $z$-score & $-0.22 \pm 2.65$ & $0.06 \pm 2.60$ & $-0.33 \pm 3.01$ & $0.43 \pm 2.53$ \\
\hline Expectancy of distant healing, $z$-score & $-0.20 \pm 2.97$ & $0.19 \pm 2.74$ & $-0.30 \pm 2.93$ & $0.27 \pm 2.77$ \\
\hline Belief in CAM, subscale belief ${ }^{\text {b }}$ & $13.9 \pm 4.6$ & $14.3 \pm 5.0$ & $13.4 \pm 4.5$ & $13.4 \pm 4.5$ \\
\hline Belief in CAM subscale holistic medicine ${ }^{\mathrm{C}}$ & $12.6 \pm 3.2$ & $12.8 \pm 3.8$ & $12.3 \pm 3.6$ & $12.5 \pm 3.6$ \\
\hline Never visits church, $\%$ & 34.6 & 24.7 & 24.4 & 23.3 \\
\hline Considers him/herself unreligious, \% & 12.2 & 14.4 & 11.3 & 16.8 \\
\hline Considers religion as very important, \% & 20.1 & 11.8 & 17.0 & 20.0 \\
\hline
\end{tabular}

Values are expressed as mean \pm SD unless otherwise indicated.

${ }^{a}$ Range of fatigue severity score: 1 (low) to 7 (high).

${ }^{\mathrm{b}}$ Holistic Complementary and Alternative Medicine Questionnaire: range of subscale Belief in CAM 5 (low) to 30 (high).

${ }^{\text {c }}$ Holistic Complementary and Alternative Medicine Questionnaire: range of subscale Holistic Health Beliefs 6 (low) to 36 (high).

healers had to be substituted due to non-adherence to the protocol and 31 healers dropped out during the trial because they withdrew consent, could no longer be reached or discontinued their healing practice.

Over 1,400 patients were screened for inclusion criteria by the study centre and 875 patients were screened at the 14 recruiting practices (fig. 1). Of these, 424 individuals did not fulfil the inclusion criteria, 22 were unable to travel, for 17 patients no recruitment centre was close enough, 1 patient withdrew consent shortly after inclusion, and 411 patients were invited and agreed to participate. Following randomisation, 2 patients did not fulfil inclusion criteria leaving 409 patients for evaluation. Of these, 13 withdrew from the study or were lost to followup. Two patients did not receive the treatment they initially were allocated to. We analysed the full intention-totreat sample of 409 patients recruited to this trial.

\section{Primary Outcome}

All groups were well balanced for relevant baseline characteristics (table 1). Table 2 shows that for each of the four groups there were small differences in the post-treatment - pre-treatment MHCS but substantial variation. Negative score values indicate higher MHCS before treatment. The analysis of covariance showed no differences in post-treatment MHCS between the groups (table 3). There was no relevant interaction between those being treated and being blinded and those being treated and not being blinded for the intervention. The only significant predictor was the pre-treatment MHCS which explained most of the overall variance of the model $\left(R^{2}: 33.7 \%\right)$.

\section{Secondary Outcome}

PHCS demonstrated some changes in three of the four groups with somewhat less variation than MHCS. Those not being treated, and knowing it, showed virtually no difference in the PHCS at completion. In the analysis of covariance of post-treatment PHCS there was a small and non-significant effect from distant healing $(1.11 ; 95 \%$ CI -0.255 to 2.473 ; $\mathrm{p}$ value $=0.11$ ). There was no interaction effect for treatment and blinding ( $\mathrm{p}$ value $=0.32$ ), but we found a mean difference of $-1.544(-2.913$ to -0.176$)$ in PHCS between the unblinded and blinded groups, indicating that those knowing they were not being treated experienced a slightly worse outcome ( $\mathrm{p}$ value $=0.03$ ) compared with all others. Figure 2 indicates that there is little difference in PHCS for the immediately treated groups and the groups who were blinded to the fact that they were not treated initially. Those who knew that they were not being treated scored on average 2.8 units lower 
Table 2. Unadjusted mean ( $\pm \mathrm{SD}$ ) component summary scores for mental and physical health (SF-36) according to treatment status and blinding in patients with CFS $(\mathrm{n}=409)$

\begin{tabular}{llllllll}
\hline & \multicolumn{2}{l}{ MHCS scores (SF-36) } & & \multicolumn{2}{l}{ PHCS scores (SF-36) } \\
\cline { 2 - 3 } & pre-treatment & post-treatment & change scores & & pre-treatment & post-treatment change scores \\
\hline Blinded and distant healing & $36.67 \pm 11.45$ & $36.37 \pm 11.98$ & $-0.29 \pm 9.54$ & & $31.02 \pm 8.09$ & $34.69 \pm 9.77$ & $3.66 \pm 6.83$ \\
Not blinded and distant healing & $34.88 \pm 10.46$ & $36.61 \pm 10.75$ & $1.74 \pm 10.25$ & & $31.75 \pm 7.94$ & $34.79 \pm 10.41$ & $3.04 \pm 7.38$ \\
Blinded and no distant healing & $37.28 \pm 10.27$ & $38.44 \pm 12.01$ & $1.16 \pm 11.07$ & & $31.78 \pm 8.83$ & $35.08 \pm 10.01$ & $3.29 \pm 7.28$ \\
Not blinded and no distant healing & $35.16 \pm 11.56$ & $35.97 \pm 11.56$ & $0.81 \pm 10.45$ & & $32.71 \pm 9.81$ & $33.46 \pm 9.68$ & $0.75 \pm 7.85$ \\
\hline
\end{tabular}

Component scores are normalised to a T distribution with a mean of 50 .

Table 3. Analysis of covariance for MHCS and PHCS scores in patients with CFS

\begin{tabular}{|c|c|c|c|c|c|}
\hline & Coefficient & $\mathrm{F}$ & $\mathrm{p}$ value & Effect (SE) & $95 \% \mathrm{CI}$ \\
\hline \multicolumn{6}{|l|}{ MHCS (SF-36) } \\
\hline Distant healing & -0.22 & 0.22 & 0.64 & $-0.44(0.93)$ & -4.04 to 3.16 \\
\hline Blinding for treatment & 0.04 & 0.01 & 0.93 & $0.08(0.94)$ & -3.52 to 3.68 \\
\hline $\begin{array}{l}\text { Interaction of distant healing and blinding for treatment } \\
\text { Covariates }\end{array}$ & 0.63 & 1.81 & 0.18 & $1.25(0.94)$ & 2.35 to 4.86 \\
\hline SF-36 MHCS scores at baseline & 0.615 & 207.2 & $<0.001$ & & \\
\hline \multicolumn{6}{|l|}{ PHCS (SF-36) } \\
\hline Distant healing & 0.55 & 2.56 & 0.111 & $1.11(0.69)$ & -0.26 to 2.47 \\
\hline Blinding for treatment & -0.77 & 4.92 & 0.027 & $-1.54(0.70)$ & -2.91 to -0.18 \\
\hline $\begin{array}{l}\text { Interaction of distant healing and blinding for treatment } \\
\text { Covariates }\end{array}$ & 0.35 & 1.01 & 0.316 & $0.70(0.70)$ & -0.65 to 2.05 \\
\hline SF-36 PHCS scores at baseline & 0.800 & 398.2 & $<0.001$ & & \\
\hline Time since onset of CFS & -0.142 & 12.05 & 0.001 & & \\
\hline Expectancy of benefit from distant healing & 0.365 & 8.75 & 0.003 & & \\
\hline
\end{tabular}

on PHCS. Besides blinding, the only covariates contributing significantly to the model and being positively correlated to PHCS were pre-treatment PHCS, duration of CFS (the longer the disease duration the lower the PHCS) and expectancy of benefit from the treatment (the higher the expectation the larger the benefit). This model explained $50.6 \%$ of overall variability of PHCS. An analysis of variance without covariates yields essentially the same results (fig. 2).

\section{Post hoc Analysis and Follow-Up}

The analysis of improvement during the trial of blinded patients according to their beliefs on treatment status yielded interesting additional insights: improvement in the secondary outcome, PHCS, in blinded and treated patients was $d=0.72$ for patients who believed they were treated $(n=19)$, and $d=0.30$ for patients who believed

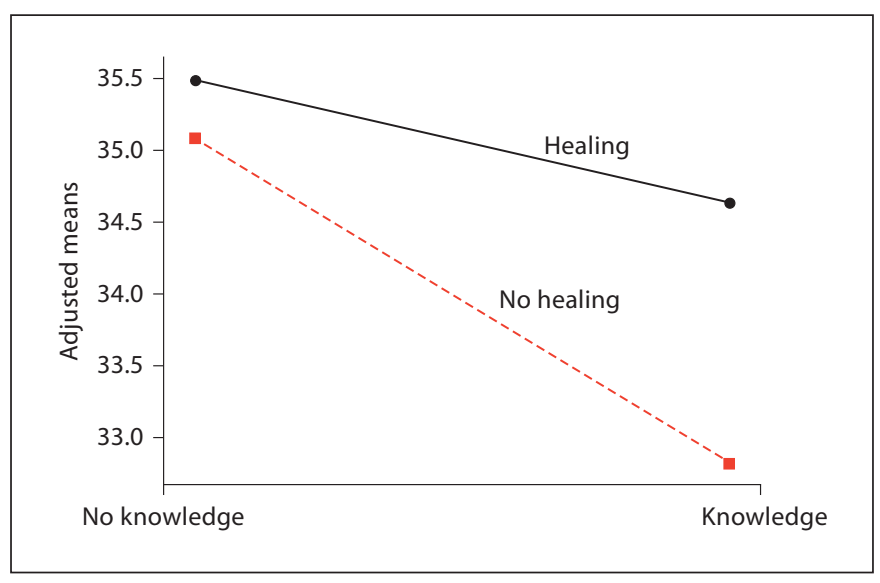

Fig. 2. Adjusted PHCS mean scores (SF-36) for patients with immediate versus deferred healing (healing and no healing) and for patients with blinding and no blinding for treatment status (no knowledge and knowledge) after 6 months. 
they had not been treated $(n=80)$. Improvement in PHSC in blinded and untreated patients who believed they were treated was $d=0.95(n=16)$, and was $d=0.2(n=74)$ for patients who believed they had not been treated. For the primary outcome, in MHSC we found similar though less pronounced trends: improvement in MHSC in blinded and treated patients who believed to be treated was $\mathrm{d}=$ 0.34 , and in those who believed that they were not treated it was $\mathrm{d}=-0.1$. In blinded and untreated patients who believed they were treated the improvement in MHCS was $d=0.71$, and in those who did not believe to be treated the MHCS deteriorated $(\mathrm{d}=-0.04)$.

Seventy-five percent of all patients responded to the follow-up SF-36 questionnaire. In general, physical health continued to improve over the follow-up period and was a further 2-3 points for PHCS in all groups. MHCS showed a more complex pattern and deteriorated 1 point in the group that had not been treated and did not know this; this group had received their treatment in the follow-up period. The group that was treated without their knowledge during the trial reported a further 4 points of improvement in the follow-up period. The group that went untreated and knew this improved 4 points after the trial, when they knew they were being treated. And those who had received their treatment knowingly during the trial had not much further improvement in the follow-up period.

\section{Discussion}

Distant healing itself appears to have no significant effect on mental or physical health in this patient group. However, the improvement seen in both treated groups and in those blinded and waiting for treatment, of approximately a third of a standard deviation in PHCS, is clinically important when considering the severity and chronicity of this illness. The group that knew they were waiting for treatment reported no change in their PHCS. The change in the two treated and one of the control groups appears to be the effect of expectation; all of these individuals were either receiving treatment or thought that they might. The only group with a stable outcome was the one that knew they would not receive immediate treatment. This interpretation is supported by our post hoc data which show that the 22 patients who believed that they had been treated improved considerably. The improvement was more than a standard deviation compared to patients who thought they had not been treated (measured 12-18 months after initiation of the treat- ment). This is also consistent with a recent meta-analysis of placebo effects in CFS which reports an effect size of $19.7 \%$ improvement from placebo in this condition [23]. However, since these data and the information about treatment beliefs are post hoc it is difficult to assess whether the individual's belief was a result of the improvement or the cause for it. It is interesting to see that the expectation of outcome was evenly distributed across groups before the trial (table 1), hence the effect is not due to initial bias. Taken together, this suggests that expectation and belief are powerful factors in improving the clinical status of people with CFS [36].

This study provides no evidence for the clinical effectiveness of distant healing in itself. This observation could have a number of explanations. Generic quality of life measures could be less responsive to subtle changes in quality of life in this population [37,38], and it is a shortcoming that no additional outcome measures are available. The inclusion of a heterogeneous group of healers could have diluted a specific treatment effect from a small group of effective healers but we found no evidence for such an effect in our data. Some authors have suggested that blinding may destroy effects of healing by generating uncertainty in patients and healers [39]. We did not find any interaction between blinding and treatment that would support this hypothesis.

We calculated that we had an $80 \%$ power to detect a standardized mean difference of $d=0.28$ when allowing for interaction so we do not believe that our trial was underpowered. We identified MHCS as the primary outcome, based on our initial pilot study. In retrospect, it appears that patients may be more likely to record improvement in physical health because of their attributions of CFS to physical causes. It has been suggested that the sceptical beliefs of trial participants and investigators might contribute to unsuccessful outcomes in distant healing. Scores of health beliefs measured with the Holistic Complementary and Alternative Medicine Questionnaire were in the average range and pre-treatment expectancies measured with the Treatment Credibility and Expectancy Scale were centred on zero in our patient population, suggesting patient equipoise in relation to healing. The study investigators' attitudes towards distant healing were also recorded and were similarly balanced. We recruited patients with CFS in Germany and Austria through a media campaign and specialized clinics. Our sample is therefore likely to be representative of people with severe CFS. Healers practised according to various traditions and came from all European countries. The findings from this trial therefore may be generalis- 
able to patients with CFS in the context of European healing traditions.

The negative findings from this trial do not imply that a therapeutic relationship and positive therapeutic intent do not have beneficial effects for individual patients. We suggest that future studies on spiritual healing particularly focus on the healer-patient relationship and the importance of belief as well as investigating the specific therapeutic effects using different methodological approaches such as qualitative research and $\mathrm{N}$-of- 1 trials.

This rigorously designed, randomized controlled and partially blinded trial in patients with CFS showed no significant effect for distant healing in MHCS (SF36) and a small effect in PHCS (SF36) which might be due to patient expectation. In addition, we found little evidence for a blinding/treatment interaction, although those who knew they were not being treated recorded poorer outcomes for the PHCS scores. Our post hoc analysis suggests that the most important clinical effects of distant healing may be related to patients' beliefs about whether they received treatment.

\section{Acknowledgements}

The authors are indebted to the healers who provided distant healing free of charge and to the patients for trial participation. The authors thank Jacqueline Canonica for data monitoring and verifying the inclusion of patients into the trial; Michael Lacour and Eberhard Schwarz for valuable help and advice; Anna Hack for her diligent help with the trial logistics; Beatrix Braack-Günther, Manfred Engel, Inge Erbe, Karl-Rainer Fabig, Peter Germann, Annamarie Heinicke, Dorothea Höck, Dieter Klein, Christoph Mai, Miriam Mück, Christian Schopper, Susanne SchunderTatzber and Margarete Werringloer for patient recruitment. We are grateful for suggestions for improvement of the manuscript to Ted Kaptchuk.

The study was funded by a grant of the European Commission, Directorate General XII, within the 5th Framework 'Quality of Life and Living Ressources' grant QG 2000-055, the Bundesamt für Wissenschaft und Bildung, Switzerland (Grant BBW No. 02.0086) and the Samueli Institute. Harald Walach was funded at the time of conducting the study by the Samueli Institute. Alain Nordmann and Heiner C. Bucher are funded by grants from Santésuisse and the Gottfried and Julia Bangerter-Rhyner Foundation. Dr. Lewith's post is funded by a grant from the Maurice Laing Foundation.

\section{References}

1 Astin JA: Why patients use alternative medicine. Results of a national study. JAMA 1998;279:1548-1553.

-2 Barnes PM, Powell-Griner E, McFann K, Nahin RL: Complementary and alternative medicine use among adults: United States, 2002. Adv Data 2004;343:1-19.

3 Benor DJ: Spiritual healing: a unifying influence in complementary therapies. Compl Ther Med 1995;3:234-238.

4 Warkentin R: Creative response to alternative medicine: clients of a modern Finnish healer in a northwestern Ontario city. Qual Health Res 2000;10:214-224.

5 Wiesendanger H: Fernheilen: Neue Hoffnung für chronisch Kranke, Bd 1: Die Vielfalt der Methoden. Schönbrunn, Lea Verlag, 2004.

6 Wiesendanger H: Fernheilen: Neue Hoffnung für chronisch Kranke, Bd 2: Fallbeispiele, Forschungen, Einwände, Erklärungen. Schönbrunn, Lea Verlag, 2004.

7 Wiesendanger H: Fernheilen: Neue Hoffnung für chronisch Kranke, Bd 3: Was Patienten bewegt: Infos, Tipps \& Warnungen. Schönbrunn, Lea Verlag, 2004.

8 Haraldsson E: Research on alternative therapies in Iceland; in Johannessen H, Launso L, Olesen SG, Staugard F (eds): Studies in Alternative Therapies 1: Contributions from the Nordic Countries. Kopenhagen, Odense University Press, 1994, pp 46-50.
9 Haraldsson E: Spiritual healing in Iceland; in Johannessen H, Launso L, Olesen SG, Staugard F (eds): Studies in Alternative Therapies 1: Contributions from the Nordic Countries. Kopenhagen, Odense University Press, 1994, pp 103-113.

10 Al-Krenawi A, Graham JR, Maoz B: The healing significance of the Negev's Bedouin Dervish. Soc Sci Med 1996;43:13-21.

11 Salib E, Youakim S: Spiritual healing in elderly psychiatric patients: a case-control study in an Egyptian psychiatric hospital. Aging Ment Health 2001;5:366-370.

12 Abbot NC: Healing as a therapy for human disease: a systematic review. J Alternative Compl Med 2000;6:159-169.

$\checkmark 13$ Astin JA, Harkness E, Ernst E: The efficacy of 'distant healing': a systematic review of randomized trials. Ann Intern Med 2000; 132:903-910.

14 Harris WS, Gowda M, Kolb JW, Strychacz CP, Vacek JL, Jones PG, Forker A, O'Keefe $\mathrm{JH}$, McCallister BD: A randomized, controlled trial of the effects of remote, intercessory prayer on outcomes in patients admitted to the coronary care unit. Arch Intern Med 1999;159:2273-2278.

15 Aviles JM, Whelan E, Hernke DA, Williams BA, Kenny KE, O’Fallon WM, Kopecky SL: Intercessory prayer and cardiovascular disease progression in a coronary care unit population: a randomized controlled trial. Mayo Clin Proc 2001;76:1192-1198.
16 Krucoff MW, Crater SW, Gallup D, Blankenship JC, Cuffe M, Guameri M, Krieger RA, Kshettry VR, Morris K, Oz M, Pichard A, Sketch MH Jr, Koenig HG, Mark D, Lee KL: Music, imagery, touch, and prayer as adjuncts to interventional cardiac care: the Monitoring and Actualisation of Noetic Trainings (MANTRA) II randomised study. Lancet 2005;366:211-217.

17 Astin JA, Stone J, Abrams DI, Moore DH, Couey P, Buscemi R, Targ E: The efficacy of distant healing for human immunodeficiency virus - results of a randomized trial. Altern Ther Health Med 2006;12:36-41.

-18 Sicher F, Targ E, Moore D, Smith HS: A randomized double-blind study of the effect of distant healing in a population with advanced AIDS. Report of a small scale study. West J Med 1998;169:356-363.

19 Chambers D, Bagnall A-M, Hempel S, Forbes C: Interventions for the treatment, management and rehabilitation of patients with chronic fatigue syndrome/myalgic encephalomyelitis: an updated systematic review. J Roy Soc Med 2006;99:506-520.

20 Rimes KA, Chalder T: Treatments for chronic fatigue syndrome. Occup Med 2005;55: 32-39.

21 Bazelmans E, Prins J, Lulofs R, van der Meer J, Bleijenberg G: Cognitive behaviour group therapy for chronic fatigue syndrome: a nonrandomised waiting list controlled study. Psychother Psychosom 2005;74:218-224. 
-22 Deale A, Husain K, Chalder T, Wessely S: Long-term outcome of cognitive behavior therapy versus relaxation therapy for chronic fatigue syndrome: a 5-year follow-up study. Am J Psychiatr 2001;158:2038-2042.

$\checkmark 23$ Cho HJ, Hotopf M, Wessely S: The placebo response in the treatment of chronic fatigue syndrome: A systematic review and metaanalysis. Psychosom Med 2005;67:301-313.

-24 Walach H, Bösch H, Haraldsson E, Marx A, Tomasson H, Wiesendanger H, Lewith G: Efficacy of distant healing - a proposal for a four-armed randomized study (EUHEALS). Forsch Komplementärmed Klass Naturheilkd 2002;9:168-176.

-25 Altman DG, Schulz KF, Moher D, Egger M, Davidoff F, Elbourne D, Gotzsche PC, Lang T: The revised CONSORT statement for reporting randomized trials: explanation and elaboration. Ann Intern Med 2001;134:663694.

-26 Fukuda K, Strauss SE, Hickie J, Sharpe MC, Dobbins JG, Komaroff A: The chronic fatigue syndrome - a comprehensive approach to its definition and study. Ann Intern Med 1994;121:953-959.

27 Bullinger M, Kirchberger I: Der SF-36 Fragebogen zum Gesundheitszustand (SF-36). Handbuch für die deutschsprachige Fragebogenversion. Göttingen, Hogrefe, 1998.
28 Güthlin C, Walach H: MOS-SF 36 - Structural equation modeling to test the construct validity of the second-order factor structure. Eur J Assess 2007;23:15-23.

29 Pardaens K, Haagdorens L, Van Wambeke P, Van den Broeck A, Van Houdenhove B: How relevant are exercise capacity measures for evaluating treatment effects in chronic fatigue syndrome? Results from a prospective, multidisciplinary outcome study. Clin Rehabil 2006;20:56-66.

30 Hautzinger M, Bailer M: Allgemeine Depressionsskala (ADS). Die deutsche Version des CES-D. Weinheim, Beltz, 1991

-31 Kleinman L, Zodet MW, Hakim Z, Aledort J, Barker C, Chan K, Krupp L, Revicki D: Psychometric evaluation of the fatigue severity scale for use in chronic hepatitis C. Qual Life Res 2000;9:499-508.

32 Lewith GT, Hyland ME, Shaw S: Do attitudes toward and beliefs about complementary medicine affect treatment outcomes? Am J Publ Health 2002;92:1604-1606.

33 Devilly GJ, Borkovec TD: Psychometric properties of the credibility/expectancy questionnaire. J Behav Ther Exp Psychiatry 2000;31:73-86.
34 Wiesendanger $\mathrm{H}$, Werthmüller L, Reuter K, Walach $\mathrm{H}$ : Chronically ill patients treated by spiritual healing improve in quality of life: results of a randomized waiting-list controlled study. J Altern Complement Med 2001;7:45-51.

35 Cohen J: Statistical Power Analysis for the Behavioral Sciences. Hillsdale, Lawrence Erlbaum, 1987.

36 Sharpe L, Ryan B, Allard S, Sensky T: Testing for the integrity of blinding in clinical trials: how valid are forced choice paradigms? Psychother Psychosom 2003;72:128-131.

37 Huber R, Lacour M, Zunder T: Die Ambulanz für Naturheilverfahren und Umweltmedizin an der Universitätsklinik Freiburg. Zwischenbericht September 1998 bis September 1999; in Albrecht H, Frühwald M (Hsg): Jahrbuch der Karl und Veronica Carstens-Stiftung. Essen, KVC Verlag, 2000, pp 15-35.

38 Prins JB, Bleijenberg G, Bazelmans E, Elving LD, de Boo TM, Severens JL, van der Wilt GJ, Spinhoven P, van der Meer JW: Cognitive behaviour therapy for chronic fatigue syndrome: a multicentre randomised controlled trial. Lancet 2001;357:841-847.

39 Dossey L: Healing Words: The Power of Prayer and the Practice of Medicine. San Francisco, Harper, 1993. 